\title{
Relationship between the laminoplasty opening size and the laminoplasty opening angle, increased sagittal canal diameter and the prediction of spinal canal expansion following open-door cervical laminoplasty
}

\author{
Zhenfang Gu $\cdot$ Aili Zhang $\cdot$ Yong Shen $\cdot$ \\ Feng Li $\cdot$ Xianze Sun $\cdot$ Wenyuan Ding
}

Received: 20 June 2014/Revised: 12 November 2014/ Accepted: 21 January 2015/Published online: 28 January 2015

(C) The Author(s) 2015. This article is published with open access at Springerlink.com

\begin{abstract}
Objective To clarify the relationship between the laminoplasty opening size (LOS), the laminoplasty opening angle (LOA) and the increase in sagittal canal diameter (SCD) and to predict the amount of canal enlargement during open-door cervical laminoplasty (ODCL).

Methods Formula describing the relationship between LOS and LOA, the increase in SCD was deduced. The parameters of pre- and postoperative computed tomography scans of 36 patients who had undergone laminoplasty surgery were measured by picture archiving and communication system (PACS) software, and the amount of canal enlargement of these patients was predicted when the opening size of laminoplasty was 8, 10, 12, 14 and $16 \mathrm{~mm}$ according to the formula.

Results For equivalent LOS, the amount of canal enlargement with each opening size differed throughout the cervical region. When the C3-C7 LOS was $10 \mathrm{~mm}$ the SCD increased $>4.1 \mathrm{~mm}$, and the canal area increased in C3-C6 $>88 \mathrm{~mm}^{2}$, and the canal area increased in $\mathrm{C} 7>80 \mathrm{~mm}^{2}$.
\end{abstract}

The manuscript submitted does not contain information about medical device(s)/drug(s).

Z. Gu $\cdot$ F. Li $\cdot$ X. Sun

Department of Spinal Surgery, The Third Hospital

of Shijiazhuang, Shijiazhuang, China

\footnotetext{
A. Zhang

Department of Respirology, Hebei General Hospital,

Shijiazhuang, China

Y. Shen $(\bowtie) \cdot$ W. Ding

Department of Spine Surgery, The Third Hospital of Hebei

Medical University, No. 139 Ziqiang Road,

Shijiazhuang 050051, China

e-mail: zhenfanggu@sina.com
}

When the C3-C7 LOS was $12 \mathrm{~mm}$, the SCD increased $>5.2 \mathrm{~mm}$, and the canal area increased in C3-C6 $>104 \mathrm{~mm}^{2}$, and the canal area increased in C7 $>94 \mathrm{~mm}^{2}$. Conclusion Formula accurately showed the relationship between the LOS and the increase in SCD achieved by ODCL. The amount of canal enlargement following ODCL could be predicted by the formula. LOS of $10-12 \mathrm{~mm}$ at C3-C7 might be optimal during ODCL.

Keywords Cervical spine - Laminoplasty opening size Spinal canal $\cdot$ Sagittal diameter $\cdot$ Cross-sectional area

\section{Introduction}

Open-door cervical laminoplasty (ODCL) [1, 2] has become a popular treatment for patients with multilevel cervical compression myelopathy resulting from cervical spondylotic myelopathy (CSM) and ossification of the posterior longitudinal ligament (OPLL). Excellent longterm results have been reported using this technique [3-7]. Clinical follow-up studies have shown that laminoplasty generally results in greater patient satisfaction and lower complication rates than laminectomy [8-12].

Inadequate increase in sagittal canal diameter (SCD) or canal volume does not relieve spinal cord compression and may lead to undesirable results after ODCL, and excessive opening of the lamina may cause the cord to migrate and extend posteriorly. In such cases, traction, tethering, and/or kinking of the nerve root secondary to posterior shift of the spinal cord may result, which has been viewed as a main factor in postoperative C5 nerve root palsy [13-18]. Wang et al. [19] pointed out that excessive opening creates a wider epidural space, leading to excessive formation of epidural scar tissue. Although the laminoplasty opening size (LOS) 
largely determines the amount of canal expansion created during laminoplasty, but the relationship between the LOS and the amount of canal expansion has remained unclear. This study aimed to clarify the relationship using a formula deduced from trigonometry and to predict the amount of canal enlargement when the opening size of laminoplasty was $8,10,12,14$ and $16 \mathrm{~mm}$ according to the formula.

\section{Materials and methods}

Patient data

We included 36 patients (27 mens, 9 womens) who underwent C3-C7 ODCL at The Third Hospital of Hebei Medical University between June 2012 and November 2013 because of CSM in 27 patients, OPLL in nine patients. The average age of the patients at surgery was 56.7 years (range 36-75 years). The median duration of symptoms before the operation was 6.6 months (range 5-67 months). A clear history of functional loss and physical findings consistent with CSM were present in all patients. They had all undergone conservative treatment for more than 3 months that had proved ineffective. All patients had a cervical lordosis angle $>10^{\circ}$. Magnetic resonance imaging confirmed cervical disc herniation or spinal canal stenosis at three or more intervertebral levels with spinal cord compression. After Institutional Review Board approval was given, each patient signed a written consent form before surgery.

\section{Formula deduction}

Preoperative and postoperative morphological changes in the cervical spinal canal were studied, after which we devised trigonometry-based formula that could describe the relationship between the LOS and the amount of canal enlargement (Fig. 1). Points E and F in Fig. 1 represent the most medial points of the bilateral laminar gutters, horizontally connected by line E-F. Line O-A represents a sagittal line through the midpoint $(\mathrm{O})$ of the posterior surface of the vertebral body, intersecting the inner edge of the lamina at point A before surgery (Fig. 1a). Point A shifts back and forms point $\mathrm{C}$. Points $\mathrm{F}$ and $\mathrm{G}$ represent the open sites of the laminae after surgery (Fig. 1b, c, d). The line $\mathrm{F}-\mathrm{G}$ indicates the size of the laminoplasty opening. The lamina angle $(\alpha)$ was defined as the angle between lines A-E and E-F. The angle $\gamma$ indicates the laminoplasty opening angle (LOA), was defined as the angle between lines $\mathrm{E}-\mathrm{G}$ and $\mathrm{E}-\mathrm{F}$. It represents the angle between the central axis of the spinous processes after surgery and the sagittal plane of the spinal vertebra. Vertical lines made through point $\mathrm{A}$ intersect line $\mathrm{E}-\mathrm{F}$ at point $\mathrm{B}$. Line $\mathrm{O}-\mathrm{B}$ intersects the inner edge of the lamina (line $\mathrm{C}-\mathrm{G}$ ) at point
D after surgery. The increases in SCD (represented by $d$ in the deduced formula) were defined as the difference between the lengths of lines $\mathrm{D}-\mathrm{B}$ and $\mathrm{A}-\mathrm{B}$, a value equivalent to the difference between lines $\mathrm{O}-\mathrm{D}$ (postsurgical diameter) and $\mathrm{O}-\mathrm{A}$ (presurgical diameter).

When the LOA was $0^{\circ}$ (Fig. 1a), points A, C, and D were actually the same point and lines A-E, C-E, and D-E were the same line. When the LOA was $60^{\circ}$ (Fig. 1d), because the distance of $\mathrm{E}-\mathrm{G}$ was equal to the distance of $\mathrm{E}-\mathrm{F}$ the triangle formed by $\mathrm{E}-\mathrm{F}-\mathrm{G}$ was an equilateral one. Line O-B represents the median sagittal line of the vertebral body. It intersects line $\mathrm{C}-\mathrm{G}$ at point $\mathrm{G}$. Thus, points $\mathrm{D}$ and $\mathrm{G}$ were actually the same point, lines $\mathrm{D}-\mathrm{E}$ and $\mathrm{G}-\mathrm{E}$ were the same line, and $\mathrm{G}-\mathrm{B}$ was the height of the equilateral triangle formed by $\mathrm{E}-\mathrm{F}-\mathrm{G}$. If $\mathrm{C}-\mathrm{E}-\mathrm{G}$ was divided by 60 , each was $\alpha / 60$. When ODCL was performed, the lamina revolved around point $\mathrm{E}$. When the LOA was $0^{\circ}-60^{\circ}$, LOA increased $1^{\circ}$, so C-E-D increased $\alpha / 60$. When the LOA was $\gamma, \mathrm{C}-\mathrm{E}-\mathrm{D}$ was $\gamma \times \alpha / 60$ and $\mathrm{D}-\mathrm{E}-\mathrm{G}$ was $\alpha-\gamma \times \alpha / 60$. Hence, D-E-B was $\gamma+(\alpha-\gamma \times \alpha / 60)$.

In triangles $\mathrm{A}-\mathrm{E}-\mathrm{B}$ and $\mathrm{D}-\mathrm{E}-\mathrm{B}$, the distance $\mathrm{B}-\mathrm{E}$ is represented by $s$ in the deduced formula. The length of line A-B is represented by $h$. The distance of D-B is the sum of the length of line A-B and increases in SCD. It is represented by $(h+d)$. We arrived at the formulas $\tan \alpha=h /$ $s$ and tanD-E-B $=(h+d) / s$ using trigonometric functions in triangles $\mathrm{A}-\mathrm{E}-\mathrm{B}$ and $\mathrm{D}-\mathrm{E}-\mathrm{B}$. The equation tanD-E-B/ $\tan \alpha=(h+d) / h$ was derived from these formulas. The final formula was thus mathematically deduced.

$$
\begin{aligned}
d & =h \times(\tan \mathrm{D}-\mathrm{E}-\mathrm{B} / \tan \alpha-1) \\
& =h \times[\tan (\gamma+\alpha-\gamma \times \alpha / 60) / \tan \alpha-1]
\end{aligned}
$$

The values of $h$ and $\alpha$ can be measured before surgery, thereby making it possible to determine the relationship between the LOA $(\gamma)$ and the increase in $\operatorname{SCD}(d)$.

Vertical lines made through points $\mathrm{E}$ intersect the line $\mathrm{F}-\mathrm{G}$ at point $\mathrm{M}$, vertical lines made through points $\mathrm{G}$ intersect the line $\mathrm{E}-\mathrm{F}$ at point $\mathrm{N}$, the distance of $\mathrm{F}-\mathrm{M}$ was equal to the distance of $\mathrm{M}-\mathrm{G}$, and $\mathrm{G}-\mathrm{N}$ was the height of triangle E-F-G. The formula for computing the size of the laminoplasty opening was as follows:

$\mathrm{F}-\mathrm{G}=2 \times \mathrm{F}-\mathrm{M}=2 \times \mathrm{E}-\mathrm{F} \times \sin (\gamma / 2)$.

The increase in canal area was equal to the area of triangle E-F-G. The formula for computing the area of triangle E$\mathrm{F}-\mathrm{G}$ was as follows:

$\mathrm{E}-\mathrm{F} \times \mathrm{G}-\mathrm{N} / 2=\mathrm{E}-\mathrm{F} / 2 \times \mathrm{E}-\mathrm{F} \times \sin \gamma$.

\section{Parametric measurements}

A computed tomography (CT) scanner (GE Sytec 2000i; GE Healthcare, Milwaukee, WI, USA) was used to perform 
Fig. 1 Radiological parameters used in the study. The angle $\alpha$ indicates the preoperative lamina angle, was defined as the angle between lines $A-E$ and $E-F$. The angle $\gamma$ indicates the laminoplasty opening angle (LOA), was defined as the angle between lines $E-G$ and $E-F$. It represents the angle between the central axis of the spinous processes after surgery and the sagittal plane of the spinal vertebra. Points $\mathrm{F}$ and $\mathrm{G}$ represent the open sites of the laminae after surgery, the line $F-G$ indicates laminoplasty opening size (LOS). The line $O-A$ indicates preoperative sagittal diameter, the line $O-D$ indicates postoperative sagittal diameter
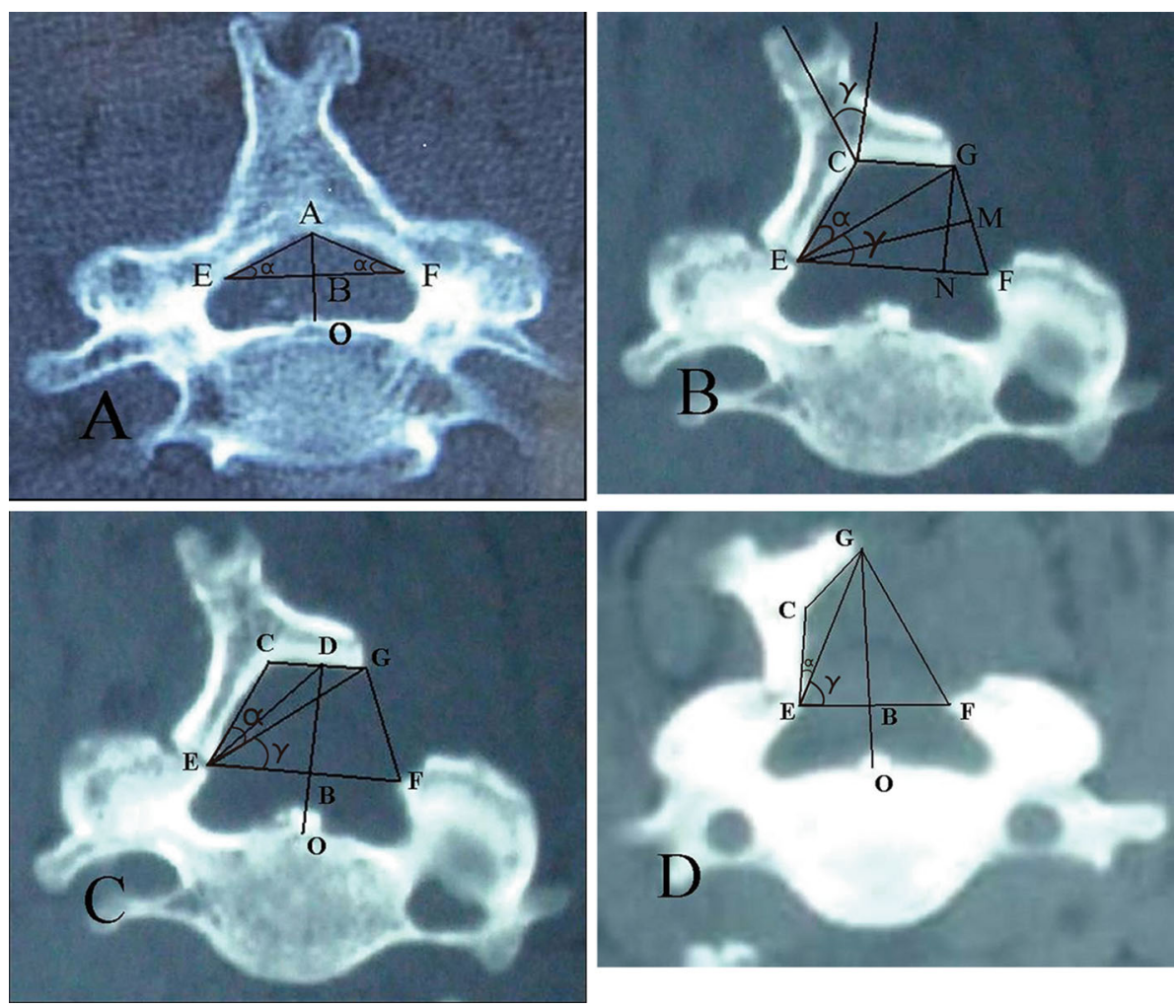

preoperative and 1-week postoperative $\mathrm{CT}$ scans on all 36 patients' spines at C1-C7 (3-mm slice thickness, window level $+300 \mathrm{HU}$, window width $1200 \mathrm{HU}$ ). Axial CT cuts made at each pedicle level from $\mathrm{C} 3$ to $\mathrm{C} 7$ were used for measurements. The preoperative and postoperative SCD, distances from points A to B and from points $\mathrm{E}$ to F, LOA $(\gamma)$, and the laminar angle $(\alpha)$ were measured using picture archiving and communication system (PACS) software with an accuracy within $0.01 \mathrm{~mm}$, or $0.01^{\circ}$. Two of the authors performed data measurements independently three times each with $\times 200$ magnification to ensure accuracy. The mean value was used for analysis. Intraobserver errors were less than $5 \%$.

Validation of the formula describing the relationship between the laminoplasty opening angle and the increase in sagittal diameter

A validation study was undertaken to assess the accuracy of the formula relating LOA to the increase in SCD. The values of $h, \gamma$, and $\alpha$ were measured, and the predicted increase in each patient's SCD at C3-C7 was computed using the formula $d=h \times[\tan (\gamma+\alpha-\gamma \times \alpha / 60) /$ $\tan \alpha-1]$. The actual SCD increase was obtained by measuring the preoperative and postoperative $\mathrm{C} 3-\mathrm{C} 7 \mathrm{SCDs}$ for each patient. Correlation between the data obtained by clinical measurement and that calculated by the formula was assessed using Pearson's correlation coefficient. The differences between these two data sets were evaluated with the paired $t$ test.

Prediction of the amount of canal enlargement

Based on the measured parameters of pre- and postoperative computed tomography scans of 36 patients, and the amount of canal enlargement of these patients were predicted when the opening size of laminoplasty was $8,10,12$, 14 and $16 \mathrm{~mm}$ using the previously described formula.

Statistical analysis

All statistical analyses were performed using Statistical Analysis System software version 9.13 (SAS Institute, Cary, NC, USA). Data are expressed as the mean \pm SD at a significance level of $P<0.05$.

\section{Results}

Data for $\mathrm{C} 3-\mathrm{C} 7$ parameters

- Preoperative lamina angle $(\alpha)$ : The largest preoperative lamina angles $(\alpha)$ were seen at $\mathrm{C} 3(31.15 \pm 2.21)$ and C7 $(32.61 \pm 2.29)$. C5 and C6 had $\alpha$ value of 
$29.49 \pm 2.62$ and $29.20 \pm 2.75$, respectively. C4 had the smallest $\alpha$ value at $28.53 \pm 2.82$ (Table 1).

- Distance between points $\mathrm{E}$ and F: The largest $\mathrm{E}$ to $\mathrm{F}$ distances were seen at C3, C4, C5, and C6 (18.36 \pm $1.30,18.51 \pm 1.53,18.64 \pm 1.50$, and $18.41 \pm 1.16$, respectively). The smallest distance was at $\mathrm{C} 7$ $(16.84 \pm 1.07)$ (Table 1).

- Distance between points A and B ( $h$ value): The largest distance from A to B was at C3 (5.55 \pm 0.54$)$. Smaller distances were seen at C4, C5, C6, and C7 (5.03 \pm $0.62, \quad 5.27 \pm 0.62, \quad 5.16 \pm 0.62$, and $5.39 \pm 0.50$, respectively) (Table 1$)$.

- Preoperative SCD (AO): Smaller preoperative SCDs (AO) were seen at C4, C5, and C6 (11.17 \pm 1.14 , $11.44 \pm 1.10$, and $11.61 \pm 1.09$, respectively). Larger preoperative SCDs (AO) were seen at $\mathrm{C} 3$ and $\mathrm{C} 7$ $(11.82 \pm 1.04$ and $12.11 \pm 1.01, \quad$ respectively $)$ (Table 1).

Differences and correlation between the data obtained by clinical measurement and the data predicted by the formula relating LOA to the increase in SCD

The comparison of the data obtained by clinical measurement and that predicted by the formula showed no significant difference $(P>0.05)$ and a high degree of correlation $(P<0.001)$. These findings support the validity of the formula relating LOA to the increase in SCD (Table 2).

Spinal canal expansion following ODCL with opening sizes from 8 to $16 \mathrm{~mm}$

Sagittal diameter, canal area were increased steadily following ODCL with opening sizes from 8 to $16 \mathrm{~mm}$. For equivalent LOS, the amount of canal expansion differed throughout the cervical region. The greatest increase in sagittal diameter was at $\mathrm{C} 4-\mathrm{C} 6$ and the smallest at $\mathrm{C} 3$ and
$\mathrm{C} 7$, the greatest increase in the canal area was at C3-C6 and the smallest at C7 (Tables 3, 4, 5).

\section{Discussion}

Optimal increase in the sagittal diameter in DDCL

Itoh and Tsuji [20] noted that a 4.1-mm enlargement of the spinal canal was ideal and could be achieved by opening the separated lamina by $8 \mathrm{~mm}$. Hirabayashi [1] stated that widening of the AP diameter by approximately 4 or $5 \mathrm{~mm}$ is sufficient for obtaining good operative result. Kohno [21] stated that good recovery group showed optimal widening by $5 \mathrm{~mm}$ in the diameter and by $95 \mathrm{~mm}^{2}$ in the canal area.

How to use this formula in the clinical practice?

Now, we make two examples in the following text. The preoperative distances from points A to B and from points $\mathrm{E}$ to $\mathrm{F}$, and the laminar angle $(\alpha)$ were measured using picture archiving and communication system (PACS) software on axial CT cuts made at C5 pedicle level before surgery (Fig. 1a).

Example 1: (1) Measurement: the distances from points A to $B$ is $4.84 \mathrm{~mm}$, and from points $E$ to $F$ is $16.52 \mathrm{~mm}$, and the laminar angle $(\alpha)$ is 30.35. (2) The calculation of $\gamma$ (LOA): If the intended LOS is $12.0 \mathrm{~mm}$, on the basis of the formula $\mathrm{F}-\mathrm{G}=2 \times \mathrm{F}-\mathrm{M}=2 \times \mathrm{E}-\mathrm{F} \times \sin (\gamma / 2), \quad 12.0=$ $2 \times 16.52 \times \sin (\gamma / 2), \quad \sin (\gamma / 2)=0.3632, \quad \gamma / 2=21.2969$, $\gamma=42.59$. (3) The calculation of $d$ : Using the formula $d=\mathrm{h} \times[\tan (\gamma+\alpha-\gamma \times \alpha / 60) / \tan \alpha-1]=4.84 \times[\tan$ $(42.59+30.35-42.59 \times 30.35 / 60) / \tan 30.35-1], \quad$ we get the value of $d, d=5.51$. In other words, when the LOS is $12 \mathrm{~mm}$, LOA is 42.59 , and $\mathrm{d}$ is $5.51 \mathrm{~mm}$.

Example 2: (1) Measurement: the distance from points A to $B$ is $6.10 \mathrm{~mm}$, and from points $E$ to $F$ is $18.84 \mathrm{~mm}$, and the laminar angle $(\alpha)$ is 32.91. (2) The calculation

Table 1 Parameters used in the study

\begin{tabular}{lrrrrr}
\hline Parameter & \multicolumn{1}{c}{ C3 } & \multicolumn{1}{c}{ C4 } & \multicolumn{1}{c}{ C5 } & C6 & C7 \\
\hline Preoperative lamina angle $(\alpha)$ & $31.15 \pm 2.21$ & $28.53 \pm 2.82$ & $29.49 \pm 2.62$ & $29.20 \pm 2.75$ & $32.61 \pm 2.29$ \\
LOA $(\gamma)$ & $43.55 \pm 7.90$ & $44.13 \pm 7.61$ & $45.43 \pm 7.25$ & $43.41 \pm 7.99$ & $44.64 \pm 6.63$ \\
Distance between points $E$ and $F(\mathrm{~mm})$ & $18.36 \pm 1.30$ & $18.51 \pm 1.53$ & $18.64 \pm 1.50$ & $18.41 \pm 1.16$ & $16.84 \pm 1.07$ \\
Distance between points $A$ and $B(\mathrm{~mm})$ & $5.55 \pm 0.54$ & $5.03 \pm 0.62$ & $5.27 \pm 0.62$ & $5.16 \pm 0.62$ & $5.39 \pm 0.50$ \\
Preoperative SCD $(\mathrm{mm})$ & $11.82 \pm 1.04$ & $11.17 \pm 1.14$ & $11.44 \pm 1.10$ & $11.61 \pm 1.09$ & $12.11 \pm 1.01$ \\
Postoperative SCD $(\mathrm{mm})$ & $18.19 \pm 2.03$ & $17.98 \pm 2.27$ & $18.49 \pm 2.13$ & $18.18 \pm 2.05$ & $17.96 \pm 1.61$ \\
\hline
\end{tabular}

Preoperative lamina angle $(\alpha)=($ left angle $\alpha+$ right angle $\alpha) / 2$

$L O A$ laminoplasty opening angle, $S C D$ sagittal canal diameter 
Table 2 Data obtained by preoperative and postoperative CT scans versus values predicted by the formula using the paired $t$ test and Pearson's correlation analysis

\begin{tabular}{llllll}
\hline Parameter & C3 & C4 & C5 & C6 & C7 \\
\hline SCD increase obtained by formula (mm) & $6.37 \pm 1.74$ & $6.81 \pm 1.85$ & $7.05 \pm 1.89$ & $6.57 \pm 1.82$ & $5.85 \pm 1.30$ \\
SCD increase obtained by measuring (mm) & $6.43 \pm 1.63$ & $6.76 \pm 1.82$ & $7.01 \pm 1.90$ & $6.53 \pm 1.79$ & $5.81 \pm 1.26$ \\
$t$ value & 1.43 & 1.38 & 1.43 & 1.26 & 1.11 \\
$P$ value & 0.1614 & 0.1773 & 0.1621 & 0.2144 & 0.2755 \\
$r$ value & 0.9905 & 0.9931 & 0.9953 & 0.9937 & 0.9886 \\
$P$ value & $<0.0001$ & $<0.0001$ & $<0.0001$ & $<0.0001$ & $<0.0001$ \\
\hline
\end{tabular}

$S C D$ sagittal canal diameter

Table 3 Increases in sagittal canal diameter at C3-C7 for laminoplasty opening sizes of 8-16 mm

\begin{tabular}{llllll}
\hline LOS $(\mathrm{mm})$ & $\begin{array}{l}\text { Increase in SCD } \\
\text { at C3 }(\mathrm{mm})\end{array}$ & $\begin{array}{l}\text { Increase in SCD } \\
\text { at C4 }(\mathrm{mm})\end{array}$ & $\begin{array}{l}\text { Increase in SCD } \\
\text { at C5 }(\mathrm{mm})\end{array}$ & $\begin{array}{l}\text { Increase in SCD } \\
\text { at C6 }(\mathrm{mm})\end{array}$ & $\begin{array}{l}\text { Increase in SCD } \\
\text { at C7 }(\mathrm{mm})\end{array}$ \\
\hline 8 & $3.09 \pm 0.09$ & $3.19 \pm 0.11$ & $3.15 \pm 0.11$ & $3.17 \pm 0.11$ & $3.08 \pm 0.10$ \\
10 & $4.08 \pm 0.14$ & $4.22 \pm 0.16$ & $4.16 \pm 0.16$ & $4.18 \pm 0.16$ & $4.09 \pm 0.15$ \\
12 & $5.20 \pm 0.20$ & $5.39 \pm 0.23$ & $5.31 \pm 0.23$ & $5.35 \pm 0.23$ & $5.27 \pm 0.22$ \\
14 & $6.52 \pm 0.30$ & $6.77 \pm 0.36$ & $6.65 \pm 0.35$ & $6.71 \pm 0.33$ & $6.67 \pm 0.34$ \\
16 & $8.09 \pm 0.45$ & $8.44 \pm 0.56$ & $8.26 \pm 0.54$ & $8.35 \pm 0.50$ & - \\
\hline
\end{tabular}

LOS laminoplasty opening size, SCD sagittal canal diameter

Table 4 Laminoplasty opening angles at C3-C7 for laminoplasty opening sizes of 8-16 mm

\begin{tabular}{llllll}
\hline LOS $(\mathrm{mm})$ & LOA at $\mathrm{C} 3\left({ }^{\circ}\right)$ & LOA at $\mathrm{C} 4\left(^{\circ}\right)$ & LOA at C5 $\left(^{\circ}\right)$ & LOA at C6 $\left(^{\circ}\right)$ & LOA at C7 $\left({ }^{\circ}\right)$ \\
\hline 8 & $25.30 \pm 1.83$ & $25.14 \pm 2.18$ & $24.95 \pm 2.05$ & $25.19 \pm 1.61$ & $27.59 \pm 1.79$ \\
10 & $31.77 \pm 2.33$ & $31.57 \pm 2.77$ & $31.33 \pm 2.60$ & $31.64 \pm 2.05$ & $34.68 \pm 2.28$ \\
12 & $38.36 \pm 2.84$ & $38.11 \pm 3.39$ & $37.82 \pm 3.18$ & $38.20 \pm 2.50$ & $41.92 \pm 2.80$ \\
14 & $45.08 \pm 3.40$ & $44.79 \pm 4.04$ & $44.44 \pm 3.79$ & $44.88 \pm 2.98$ & $49.34 \pm 3.36$ \\
16 & $51.97 \pm 3.99$ & $51.64 \pm 4.75$ & $51.22 \pm 4.45$ & $51.74 \pm 3.51$ & - \\
\hline
\end{tabular}

LOS laminoplasty opening size, LOA laminoplasty opening angle

Table 5 Increases in canal area at C3-C7 for laminoplasty opening sizes of 8-16 mm

\begin{tabular}{lccccc}
\hline LOS $(\mathrm{mm})$ & $\begin{array}{c}\text { Increases in canal } \\
\text { area at C3 }\left(\mathrm{mm}^{2}\right)\end{array}$ & $\begin{array}{c}\text { Increases in canal } \\
\text { area at C4 }\left(\mathrm{mm}^{2}\right)\end{array}$ & $\begin{array}{c}\text { Increases in canal } \\
\text { area at C5 }\left(\mathrm{mm}^{2}\right)\end{array}$ & $\begin{array}{c}\text { Increases in canal } \\
\text { area at C6 }\left(\mathrm{mm}^{2}\right)\end{array}$ & $\begin{array}{c}\text { Increases in canal } \\
\text { area } \mathrm{at} \mathrm{C7}\left(\mathrm{mm}^{2}\right)\end{array}$ \\
\hline 8 & $71.66 \pm 5.31$ & $72.28 \pm 6.28$ & $72.81 \pm 6.13$ & $71.89 \pm 4.77$ & $65.44 \pm 4.41$ \\
10 & $88.30 \pm 6.74$ & $89.09 \pm 7.80$ & $89.76 \pm 7.78$ & $88.60 \pm 6.05$ & $80.41 \pm 5.61$ \\
12 & $104.07 \pm 8.23$ & $105.02 \pm 9.74$ & $105.84 \pm 9.50$ & $104.43 \pm 7.39$ & $94.40 \pm 6.88$ \\
14 & $118.74 \pm 9.82$ & $119.87 \pm 11.62$ & $120.85 \pm 11.32$ & $119.17 \pm 8.81$ & $107.19 \pm 8.25$ \\
16 & $132.09 \pm 11.54$ & $133.41 \pm 13.65$ & $134.56 \pm 13.28$ & $132.61 \pm 10.34$ & - \\
\hline
\end{tabular}

LOS laminoplasty opening size

of $\gamma$ (LOA): if the intended increase in sagittal canal diameter after surgery is $5.0 \mathrm{~mm}$, that is, $d=5.0 \mathrm{~mm}$. Using the formula $d=h \times[\tan (\gamma+\alpha-\gamma \times \alpha / 60) /$ $\tan \alpha-1], \quad 5.0=6.10 \times[\tan (\gamma+32.91-\gamma \times 32.91 / 60) /$ $\tan 32.91-1]$, we get the value of $\gamma, \gamma=37.12$. (3) The calculation of LOS: on the basis of the formula F- 
$\mathrm{G}=2 \times \mathrm{F}-\mathrm{M}=2 \times \mathrm{E}-\mathrm{F} \times \sin (\gamma / 2)=2 \times 18.84 \times \sin$ $(37.12 / 2)$, LOS $=12.0 \mathrm{~mm}$. In other words, when the intended value of $d$ is $5.0 \mathrm{~mm}$, LOA is 37.12 , and LOS is $12.0 \mathrm{~mm}$.

The above-mentioned formula would help us plan precisely the LOS to return to approximately normal dimensions of the spinal canal on the basis of preoperative measured E-F, $\alpha$ and $h$. Because individual E-F, $\alpha$ and $h$ value is variable, the above-mentioned formula enables ODCLs to be individualized based on an accurate size of the laminoplasty opening, preventing inadequate or excessive opening.

Influence of increased size of the postsurgical SCD

On the basis of the formula $d=h \times[\tan (\gamma+\alpha-\gamma \times \alpha)$ $60) / \tan \alpha-1]$ and the formula $\mathrm{F}-\mathrm{G}=2 \times \mathrm{F}-$ $\mathrm{M}=2 \times \mathrm{E}-\mathrm{F} \times \sin (\gamma / 2)$, the $d$ value (postsurgical increase in SCD) was directly proportional to the values of $h$ and $\gamma$ and varied inversely with $\alpha$. For ODCL within the same vertebral segment, the values of $h$ and $\alpha$ were the same, and the increase in postsurgical SCD was dependent on the LOS. The greater the LOS, the greater was the increase in SCD.

For ODCL of the same segment in different patients or different segments in the same patient, the values of $h, \alpha$, and the distance between points $\mathrm{E}$ and $\mathrm{F}$ varied. Therefore, the increase in SCD after laminoplasty differed even when the LOS was the same. In this study, when the LOS was $12 \mathrm{~mm}$, increases in the SCD of C3-C7 differed (values were 5.20, 5.39, 5.31, 5.35, and $5.27 \mathrm{~mm}$, respectively). The largest increase in SCD was at C4-C6. The smallest increase was at $\mathrm{C} 3$ and $\mathrm{C} 7$ because of the smaller distance between points $\mathrm{E}$ and $\mathrm{F}$ and the greater preoperative laminar angle.

The position of the lateral hinges is closely related to the $\alpha$ value, $h$ value, and distance between points $\mathrm{E}$ and $\mathrm{F}$. As these three values changed with the position of the lateral hinges, the SCD was affected. For same-segment ODCL with the same LOS, the closer was the position of the lateral hinges to the inside of the lamina, the lower were the $\alpha$ and $h$ values, the less was the distance between points $\mathrm{E}$ and F, and the smaller was the increase in SCD. As most authors believe that the lateral hinges should be positioned at the medial border of the lamina-lateral mass junction [15, 22-24], we followed this positioning in the current study.

\section{Optimal LOS following ODCL}

In this study, when the C3-C7 LOS was $10 \mathrm{~mm}$, the increase in the SCD was $4.1 \mathrm{~mm}$, and the increase in the cross-sectional area of the spinal canal in C3-C6 was
$88 \mathrm{~mm}^{2}$, and the increase in the cross-sectional area of the spinal canal in $\mathrm{C} 7$ was $80 \mathrm{~mm}^{2}$.

The optimal increase in the sagittal diameter of the stenotic canal by laminoplasty is $>4-5 \mathrm{~mm}[1,21]$. Therefore, when the LOS was $<10 \mathrm{~mm}$ at $\mathrm{C} 3-\mathrm{C} 7$, the postoperative SCD and canal volume increases were inadequate and would not relieve spinal cord compression.

While devising the formula, we found that the increase in the SCD reached the maximum value when the LOA was $60^{\circ}$ or when the LOS equal the distance between points $\mathrm{E}$ and $\mathrm{F}$. The SCD obtained when the LOA was $>60^{\circ}$ or when the LOS was greater than the distance between points $\mathrm{E}$ and $\mathrm{F}$ was less than that when the LOA was $60^{\circ}$ or when the LOS equal the distance between points $\mathrm{E}$ and $\mathrm{F}$ (Fig. 1). Therefore, the LOA cannot exceed $60^{\circ}$ (the LOS cannot exceed the distance between points $\mathrm{E}$ and $\mathrm{F}$ ) for ODCL.

Maezumi [25], using intraoperative ultrasonography, showed that anteriorly the spinal cord was separated from the osteophyte and that the ossification in the narrowest level of the spinal canal was decompressed successfully in most cases if the angle of the lamina was $\leq 45^{\circ}$. Tsuzukil et al. [26] noted that a smaller laminar opening might suppress posterior shift of the dural tube. Such suppression with balanced traction forces on the bilateral roots might reduce the traction effect of the bulging dural tube on the roots, which can prevent postoperative $\mathrm{C} 5$ root injury. We think that if spinal cord compression was alleviated completely, the spinal cord would have a greater chance to recover its functions. There is a positive correlation between the chance for the spinal cord to recover its functions and the degree of spinal cord decompression. However, it is not to say that if the LOS was larger the spinal cord would have a greater chance to recover its functions. In this study, when the C3-C7 LOS was $12 \mathrm{~mm}$, the increase in the SCD was $>5.2 \mathrm{~mm}$, and the increase in the cross-sectional area of the spinal canal in C3-C6 was $>104 \mathrm{~mm}^{2}$, and the increase in the cross-sectional area of the spinal canal in $\mathrm{C} 7$ was $>94 \mathrm{~mm}^{2}$.

In conclusion, widening of the AP diameter by approximately $4.1-5.2 \mathrm{~mm}$ is obtained when LOS of $10-12 \mathrm{~mm}$ at $\mathrm{C} 3-\mathrm{C} 7$ is made, which is sufficient for obtaining good operative result [1, 21]. But, in some patients who suffered from serious ossification of the posterior longitudinal ligament, the greater opening size should be used to achieve a wider spinal canal than used in patients with cervical spondylotic myelopathy.

Study limitations

There are some limitations in this study. When the LOA was $\leq 60^{\circ}$ and the lateral gutter positioning was symmetrical, the formula $d=h \times[\tan (\gamma+\alpha-\gamma \times \alpha / 60) /$ 
$\tan \alpha-1]$ accurately revealed the correlation between the LOA and the SCD increase needed during ODCL. If the lateral gutter positioning was asymmetrical, there was a small difference from the calculated result.

An additional variable is the amount of bone removed when the laminae are opened. The surgeon, the technique, and instruments used influence the quantity of bone lost. The amount of bone removed is transverse of width of the cutting laminae. The removed bone was not taken into account in the current study. In reality, the size of the laminoplasty opening should equal the value calculated by the formula plus the diameter of the removed bone.

\section{Conclusions}

Formula accurately showed the relationship between the LOS and the increase in SCD achieved by ODCL. The amount of canal enlargement following ODCL could be predicted by the formula. Widening of the AP diameter by approximately $4.1-5.2 \mathrm{~mm}$ is obtained when LOS of $10-12 \mathrm{~mm}$ at $\mathrm{C} 3-\mathrm{C} 7$ is made, which might be optimal during ODCL. Besides, the LOA cannot exceed $60^{\circ}$ (the LOS cannot exceed the distance between points $\mathrm{E}$ and $\mathrm{F}$ ) for ODCL.

Conflict of interest No funds were received in support of this work. No benefits in any form have been or will be received from a commercial party related directly or indirectly to the subject of this manuscript.

Open Access This article is distributed under the terms of the Creative Commons Attribution License which permits any use, distribution, and reproduction in any medium, provided the original author(s) and the source are credited.

\section{References}

1. Hirabayashi K, Watanabe K, Wakano K, Suzuki N, Satomi K, Ishii Y (1983) Expansive ODCL for cervical spinal stenotic myelopathy. Spine 8(7):693-699

2. Hirabayashi K, Satomi K (1988) Operative procedure and results of expansive ODCL. Spine 13:870-876

3. Satomi K, Nishu Y, Kohno T et al (1994) Long-term follow-up studies of open-door expansive laminoplasty for cervical stenotic myelopathy. Spine 19:507-510

4. Kimura I, Shingu H, Nasu Y (1995) Long-term follow-up of cervical spondylotic myelopathy treated by canal-expansive laminoplasty. J Bone Joint Surg Br 77:956-961

5. Ogawa Y, Toyama Y, Chiba K, Matsumoto M, Nakamura M, Takaishi H, Hirabayashi H, Hirabayashi K (2004) Long-term results of expansive ODCL for ossification of the posterior longitudinal ligament of the cervical spine. J Neurosurg Spine 1(2): $168-174$

6. Chiba K, Ogawa Y, Ishii K et al (2006) Long-term results of expansive open -door laminoplasty for cervical myelopathy average 14-year follow-up study. Spine 31(26):2998-3005
7. Matsumoto M, Watanabe K, Hosogane N, Tsuji T, Ishii K, Nakamura M, Chiba K, Toyama Y (2012) Impact of lamina closure on long-term outcomes of ODCL in patients with cervical myelopathy: minimum 5-year follow-up study. Spine (Phila Pa 1976) 37(15):1288-1291. doi:10.1097/BRS.0b013e3182498434

8. Herkowitz HN (1988) A comparison of anterior cervical fusion, cervical laminectomy, and cervical laminoplasty for the surgical management of multiple level spondylotic radiculopathy. Spine 13:774-780

9. Kaminsky SB, Clark CR, Traynelis VC (2004) Operative treatment of cervical spondylotic myelopathy and radiculopathy. A comparison of laminectomy and laminoplasty at five year average follow-up. Iowa Orthop J 24:95-105

10. Hardman J, Graf O, Kouloumberis PE, Gao WH, Chan M, Roitberg BZ (2010) Clinical and functional outcomes of laminoplasty and laminectomy. Neurol Res 32(4):416-420. doi:10. 1179/174313209X459084

11. Manzano GR, Casella G, Wang MY, Vanni S, Levi AD (2012) A prospective, randomized trial comparing expansile cervical laminoplasty and cervical laminectomy and fusion for multilevel cervical myelopathy. Neurosurgery 70:264-277

12. Yang L, Gu Y, Shi J, Gao R, Liu Y, Li J, Yuan W (2013) Modified plate-only ODCL versus laminectomy and fusion for the treatment of cervical stenotic myelopathy. Orthopedics 36(1):e79-e87. doi:10.3928/01477447-20121217-23

13. Imagama S, Matsuyama $Y$, Yukawa $Y$ et al (2010) C5 palsy after cervical laminoplasty: a multicentre study. J Bone Joint Surg $\mathrm{Br}$ 92:393-400. doi:10.1302/0301-620X.92B3.22786

14. Tsuzuki N, Zhogshi L, Abe R, Saiki K (1993) Paralysis of the arm after posterior decompression of the spinal cord: 1. Anatomical investigation of the mechanism of paralysis: analysis of clinical findings. Eur Spine J 2(4):191-196

15. Uematsu Y, Tokuhashi Y, Matsuzaki H (1998) Radiculopathy after laminoplasty of the cervical spine. Spine 23(19):2057-2062

16. Hatta Y, Shiraishi T, Hase $\mathrm{H}$ et al (2005) Is posterior spinal cord shifting by extensive posterior decompression clinically significant for multisegmental cervical spondylotic myelopathy? Spine 30(21):2414-2419

17. Tsuzuki N, Abe R, Saiki K, Zhongshi L (1996) Extradural tethering effect as one mechanism of radiculopathy complicating posterior decompression of the cervical spinal cord. Spine 21(2):203-211

18. Dai L, Ni B, Yuan W, Jia L (1998) Radiculopathy after laminectomy for cervical compression myelopathy. J Bone Joint Surg $\mathrm{Br} 80(5): 846-849$

19. Wang XY, Dai LY, Xu HZ, Chi YL (2006) Prediction of spinal canal expansion following cervical laminoplasty: a computersimulated comparison between single and double-door techniques. Spine 31(24):2863-2870

20. Itoh T, Tsuji H (1985) Technical improvements and results of laminoplasty for compressive myelopathy in the cervical spine. Spine 10(8):729-736

21. Kohno K, Kumon Y, Oka Y, Matsui S, Ohue S, Sakaki S (1997) Evaluation of prognostic factors following expansive laminoplasty for cervical spinal stenotic myelopathy. Surg Neurol 48(3):237-245

22. Patel CK, Cunningham BJ, Herkowitz HN (2002) Techniques in cervical laminoplasty. Spine J 2:450-455

23. O'Brien MF, Peterson D, Casey AT et al (1996) A novel technique for laminoplasty augmentation of spinal canal area using titanium miniplate stabilization: a computerized morphometric analysis. Spine 21:474-483

24. Kimura S, Gomibuchi F, Shimoda $\mathrm{H}$ et al (2000) Boomerang deformity of cervical spinal cord migrating between split laminae after laminoplasty. Eur Spine J 9:144-151 
25. Maezumi H (1989) Cervical radiculopathy after the posterior decompression of the cervical cord. Kanto J Orthopedic Traumatol 20:324-328
26. Tsuzuki N, Abe R, Saiki K, Okai K (1993) Paralysis of the arm after posterior decompression of the cervical spinal cord. II. Analyses of clinical findings. Eur Spine J 2(4):197-202 